\title{
Effects of Systemic and Local Phenylephrine and Arginine Vasopressin Infusions in Conscious Postnatal Sheep
}

\author{
SITHEMBISO C. VELAPHI, TIMOTHY ROY, KEVIN DESPAIN, AND CHARLES R. ROSENFELD \\ Department of Pediatrics, Division of Neonatal-Perinatal Medicine, University of Texas Southwestern \\ Medical Center at Dallas, Dallas, Texas, 75390
}

\begin{abstract}
Mean arterial pressure (MAP) increases after birth, however, the mechanisms remain unclear. Systemic angiotensin II (ANG II) infusions increase MAP in newborn sheep, but the direct effects of ANG II on peripheral vascular resistance (PVR) are minimal. Thus, its systemic pressor effects may reflect release of other pressor agents, e.g. $\alpha$-agonists and/or AVP, suggesting they contribute to postnatal regulation of MAP and PVR. To address this, we performed studies in conscious sheep at 7-14, 15-21, and $22-35$ d postnatal, infusing phenylephrine (PE) or AVP systemically or intra-arterially into the hindlimb while measuring MAP, heart rate (HR), and femoral blood flow (FmBF). Basal MAP and FmBF rose, whereas HR and femoral vascular resistance $(F m V R)$ fell $(p \leq 0.03)$ during the first month postnatal. Although systemic PE and AVP dose dependently increased MAP and FmVR and decreased FmBF and HR $(p<0.001$, ANOVA) at all ages, responses were not age dependent. Notably, increases in FmVR exceeded increases in MAP, and responses to PE appeared to exceed AVP $(p<0.05)$. Hindlimb infusions of both agents decreased FmBF and increased FmVR dose depen-
\end{abstract}

\section{ABSTRACT}

dently ( $p<0.001$, ANOVA) at all ages without altering MAP or HR. These responses also were not age dependent. Unlike ANG II, PE and AVP directly increase PVR in newborn sheep. Moreover, FmVR increases more than MAP at all doses, suggesting these agonists may contribute to postnatal MAP regulation and could mediate the effects of systemic ANG II on postnatal MAP.

(Pediatr Res 58: 58-65, 2005)

ANG II, angiotensin II
AVP, arginine vasopressin
FmBF, femoral blood flow
FmVR, femoral vascular resistance
HR, heart rate
MAP, mean arterial pressure
PE, phenylephrine
PVR, peripheral vascular resistance
VSM, vascular smooth muscle

The transition at birth is accompanied by increases in MAP that occur in at least two phases. There is an initial rapid rise soon after birth, likely due to the removal of the low-resistance placental vascular bed and closure of several fetal vascular shunts. Simultaneous with this is an elevation in circulating levels of catecholamines, ANG II, and AVP (1-4). The second phase is characterized by a gradual rise in MAP that occurs over several days and appears to be developmentally regulated (1,5-9). The mechanisms regulating these changes in MAP are poorly understood and could include the postnatal clearance of placentally derived vasodilators, e.g. prostacyclin, nitric oxide, and estrogen $(10,11)$, increases in central sympathetic outflow

Received October 7, 2004; accepted October 28, 2004.

Correspondence: Charles R. Rosenfeld, M.D., Department of Pediatrics, UT Southwestern Medical Center at Dallas, 5323 Harry Hines Blvd., Dallas, TX 75390-9063; e-mail: charles.rosenfeld@utsouthwestern.edu

Supported in part by the George L. MacGregor Professorship in Pediatrics and Grant HD-08783 from the National Institutes of Health.

DOI: 10.1203/01.PDR.0000163395.07153.90
(12), age-dependent changes in VSM receptor expression or function (13), maturational and/or function changes in VSM (14), or increases in cardiac output (15). Although cardiac output increases in absolute terms, values (measured in milliliter per minute per kilogram) are reported to fall in the first month after birth (15).

Alternatively, changes in either the availability or vascular responsiveness to circulating vasoactive substances may contribute to the regulation of postnatal MAP. For example, ANG II, catecholamines, and AVP modulate MAP in the fetus and adult (1,16-19) and might also contribute to postnatal regulation of MAP. This could occur through an increase in their direct effects on PVR, which might be due to decreases in the synthesis of local vasodilators $(10,11)$ or increases in VSM sensitivity.

Indeed, the responses to norepinephrine and AVP in the isolated ear artery of the developing sheep increase with increasing postnatal age (20). Although systemic infusions of ANG II in conscious postnatal sheep increase MAP and PVR, 
as reflected by increases in FmVR, arterial infusions directly into the hindlimb do not alter FmBF or FmVR (21). Furthermore, these responses are similar throughout the first postnatal month $(21,22)$, mirroring the prevalence of the nonvasoconstricting type-2 ANG II receptor subtype (AT2 ) in peripheral VSM until 3-4 wk postnatal $(13,23)$. Thus, the rise in basal MAP after birth is unlikely due to increases in vascular sensitivity to ANG II.

Catecholamines and AVP also modify postnatal MAP and mediate these responses through different receptors; therefore, their effects on MAP and PVR may differ from ANG II. Furthermore, their secretion increases in the presence of ANG II (24-26). Woods et al. (17) observed that $\alpha$-adrenergic blockade decreased MAP in postnatal sheep, but this was attenuated with increasing age. Thus, the contribution of catecholamines to the maintenance of postnatal MAP and vascular tone is developmentally regulated (17,27). Although AVP increases MAP dose dependently in fetal sheep (19), its contribution to postnatal MAP regulation is unclear. Furthermore, no one has compared the effects of systemic and peripheral arterial infusions of an $\alpha$-agonist or AVP on neonatal pressor responses and PVR. Therefore, the objectives of the present study were 1) to examine the effects of PE, an $\alpha 1$-agonist, and AVP on pressor responses and PVR, and 2) to determine whether they elicit age-dependent changes in vascular reactivity that contribute to the regulation of postnatal blood pressure in conscious postnatal sheep.

\section{METHODS}

Animal preparation. Six newborn sheep were serially studied between 7 and $35 \mathrm{~d}$ postnatal. Surgery was performed at 3-5 d of life using procedures previously described (21). Briefly, each animal received preoperative subcutaneous atropine $(0.088 \mathrm{mg} / \mathrm{kg})$ followed by sodium pentobarbital $(7.5-10$ $\mathrm{mg} / \mathrm{kg}$ i.v.) and $1 \%$ ketamine hydrochloride $(1-2 \mathrm{mg} / \mathrm{kg}$ i.v.) via a percutaneous jugular venous catheter. During surgery, $1 \%$ ketamine hydrochloride (1 $\mathrm{mg} / \mathrm{kg}$ i.v.) was administered to maintain deep anesthesia. Through an inguinal incision in one hindlimb, polyvinyl catheters containing heparinized saline (250 units $/ \mathrm{mL}$ ) were implanted into the femoral artery 12.5 and $7.5 \mathrm{~cm}$ for cardiovascular monitoring and blood sampling, respectively, and the femoral vein $(15 \mathrm{~cm})$ for systemic infusions of PE and AVP. An inguinal incision was made in the contralateral hindlimb, and a $3.0-4.0 \mathrm{~mm}$ I.D. electromagnetic flow probe (Carolina Medical, King, NC) was implanted on the femoral artery proximal to the branching of the superficial saphenous artery to continuously measure FmBF. A polyethylene catheter (PE 50) filled with heparinized saline (250 units $/ \mathrm{mL}$ ) was inserted into the superficial saphenous artery with the tip lying at the junction with the femoral artery for intra-arterial infusions of $\mathrm{PE}$ and AVP. The catheters were flushed with heparinized saline $(250$ units $/ \mathrm{mL})$ and closed with metal pins. The flow probe leads and catheters were brought out to the flank through a subcutaneous tunnel and placed in a canvas pouch attached to the skin with sterile steel pins. The skin incisions were closed in one layer with surgical staples. During surgery, animals received $10 \%$ dextrose and isotonic saline at $20 \mathrm{~mL} / \mathrm{kg} \cdot \mathrm{h}$ to prevent hypoglycemia and hypovolemia. All animals received banamine $(0.1 \mathrm{~mL}$ i.v., Schering-Plough Animal Health, Union, NJ) for pain and intramuscular penicillin (60,000 units) and gentamicin $(7.5 \mathrm{mg})$ for prophylaxis immediately after surgery and on the first two postoperative days. Immediately after surgery, animals received $70 \mathrm{~mL} / \mathrm{kg}$ of 5\% dextrose and isotonic saline over $4 \mathrm{~h}$ and were maintained under a heated warmer until they had fully recovered from the anesthesia.

After recovery, animals were returned to their mothers for feeding, but were removed the first night and monitored in a postoperative recovery facility within the Animal Resources Center. Subsequently, each animal was kept with its mother except during the time of an experiment. Catheters were flushed daily with sterile heparinized saline $(250$ units $/ \mathrm{mL})$ to maintain patency. All animals received intramuscular penicillin (60,000 units) and gentamicin (7.5 $\mathrm{mg}$ ) at the completion of each study for prophylaxis. These studies were approved by the Institutional Animal Care and Use Committee at UT Southwestern Medical Center at Dallas.

Experimental protocols. Experiments were performed after the animals were considered to have recovered from surgery and anesthesia; thus, no animal was studied before postoperative $\mathrm{d} 4$. Studies were performed with the animals in a sling, and only after a $30-40 \mathrm{~min}$ period demonstrating stable hemodynamic parameters and arterial blood gases.

The experiments were divided into two protocols to assess cardiovascular responses to systemic and intra-arterial hindlimb infusions of PE and AVP.

Protocol 1: systemic infusions. Four doses of PE (1.0, 2.0, 4.0, and 8.0 $\mu \mathrm{g} / \mathrm{kg} \cdot \mathrm{min}$, Sigma Chemical Co., St. Louis, MO) and AVP (0.97, 1.29, 2.58, and $5.16 \mathrm{mU} / \mathrm{kg} \cdot \mathrm{min}$, Lyphomed, Des Plaines, IL) that had previously been studied in our laboratory were used in the present studies $(19,28)$. Because animals were actively growing, doses were corrected for weight $(\mu \mathrm{g} / \mathrm{kg} \cdot \mathrm{min}$ or $\mathrm{mU} / \mathrm{kg} \cdot \mathrm{min}$ ) to account for increases in weight during the study period. After a 30-min stabilization period, doses of one vasoconstrictor were randomly infused through the femoral venous catheter using a constant infusion pump (Harvard Apparatus, South Natick, MA). Each dose was continuously infused for $15 \mathrm{~min}$ to achieve steady-state hemodynamic responses while continuously monitoring MAP and HR with a pressure transducer (model P23XL, Gould Corp., Cleveland, $\mathrm{OH}$ ) and FmBF with an electromagnetic flow meter (model 551, Carolina Medical). The signals were recorded on an eight-channel recorder (model RS 3800, Gould Corp.) and on the PONEMAH Data Acquisition System (Gould Corp.). At least 20 min was allowed between doses so that hemodynamic parameters returned to baseline values. FmVR was calculated from MAP divided by FmBF before and at 12-15 min during steady-state responses. Arterial blood $(0.3 \mathrm{~mL})$ was obtained for measurement of blood gases before each dose; hematocrit was measured before and at the end of each experiment. Samples were analyzed with a blood gas analyzer (model 113, Instrumentation Laboratory, Lexington, MA) and the Wintrobe capillary method for hematocrit. Each agent was studied after a 24-h recovery period to minimize residual effects from the previous agent studied. Animals were studied at three ages, 7-14 d, 15-21 d, and 22-35 d postnatal, to assess age-dependent or developmental alterations.

Protocol 2: intra-arterial infusions. To determine the effects of each agent on PVR independent of systemic effects and changes in MAP or perfusion pressure, we examined the responses to local arterial infusions of each agent via the superficial saphenous artery catheter (21). To more accurately compare the effects of systemic and local infusions of each agent, the hindlimb should be exposed to similar plasma concentrations of the agent. Therefore, we calculated the estimated arterial concentrations $(\mathrm{ng} / \mathrm{mL}$ or $\mu \mathrm{U} / \mathrm{mL})$ that might be achieved during continuous systemic infusions, using the systemic infusion rate $(\mu \mathrm{g} / \mathrm{min}$ or $\mathrm{mU} / \mathrm{min})$ divided by the estimated cardiac output $(\mathrm{mL} / \mathrm{min})$ determined from observations of Woods et al. (15). These were corrected for postnatal age and weight for each animal and assumed the presence of steady-state conditions. The local PE or AVP infusion rates (ng/min or $\mu \mathrm{U} / \mathrm{min}$ ) were then calculated from the product of the estimated arterial plasma concentration ( $\mathrm{ng} / \mathrm{mL}$ or $\mu \mathrm{U} / \mathrm{mL}$ ) desired and multiplied by $\mathrm{FmBF}(\mathrm{mL} / \mathrm{min})$. Because of changes in postnatal weight and cardiac output during the study period, a broad range of PE and AVP arterial concentrations were studied, using rates of infusion that were $0.16-17.7 \mathrm{ng} / \mathrm{min}$ and $0.13-12.6 \mu \mathrm{U} / \mathrm{min}$, respectively. Each animal received four randomly infused arterial doses of each agent. Studies of intra-arterial PE or AVP always followed the assessment of systemic infusions and were performed on the same day after a recovery period or within $24 \mathrm{~h}$ of systemic infusions to minimize potential agedependent changes (Table 1). The order of drug was randomized.

Data analysis. Responses were analyzed as the absolute and relative changes, using measurements obtained immediately before each dose of PE or AVP and at $12-15$ min during the steady-state responses to continuous PE or AVP infusions. To compare responses by hemodynamic parameters with different units, e.g. MAP, FmBF, and FmVR, and changes across postnatal age, data are presented as the relative or percentage change $(\% \Delta)$ from baseline $(21,29)$. One-way ANOVA for repeated measures was used to analyze the changes in hemodynamic parameters across postnatal ages and across doses within each age group. When significance $(p<0.05)$ was observed, NewmanKeuls multiple comparisons were used to define differences between age groups and/or doses. Paired $t$ test was used to determine changes from baseline.

ANOVA for multiple comparisons was used to examine dose-response relationships, followed by Newman-Keuls to define differences at $p<0.05$. Nonparametric analysis was used where appropriate. Two-way ANOVA was used to assess differences between hemodynamic parameters. Regression analysis was also used to examine changes across doses and interactions between hemodynamic variables. Data are presented as mean \pm SEM. Reported differences are considered significant at $p<0.05$. 
Table 1. The age in days at which studies of systemic and intra-arterial infusions of phenylephrine and arginine vasopressin were performed in newborn sheep

\begin{tabular}{|c|c|c|c|c|}
\hline \multirow[b]{2}{*}{ Animal no. } & \multicolumn{2}{|c|}{ Phenylephrine } & \multicolumn{2}{|c|}{ Arginine vasopressin } \\
\hline & Systemic & Intra-arterial & Systemic & Intra-arterial \\
\hline \multirow[t]{3}{*}{1} & $12 \mathrm{~d}$ & - & $13 \mathrm{~d}$ & $13 \mathrm{~d}$ \\
\hline & $18 \mathrm{~d}$ & $18 \mathrm{~d}$ & $24 \mathrm{~d}$ & $24 \mathrm{~d}$ \\
\hline & $30 \mathrm{~d}$ & $30 \mathrm{~d}$ & $32 \mathrm{~d}$ & $32 \mathrm{~d}$ \\
\hline \multirow[t]{2}{*}{2} & $16 \mathrm{~d}$ & $16 \mathrm{~d}$ & $13 \mathrm{~d}$ & $13 \mathrm{~d}$ \\
\hline & $24 \mathrm{~d}$ & $24 \mathrm{~d}$ & $20 \mathrm{~d}$ & $20 \mathrm{~d}$ \\
\hline \multirow[t]{3}{*}{3} & $7 \mathrm{~d}$ & $9 \mathrm{~d}$ & $11 \mathrm{~d}$ & $12 \mathrm{~d}$ \\
\hline & $24 \mathrm{~d}$ & $25 \mathrm{~d}$ & $17 \mathrm{~d}$ & $18 \mathrm{~d}$ \\
\hline & $35 \mathrm{~d}$ & $35 \mathrm{~d}$ & $28 \mathrm{~d}$ & $30 \mathrm{~d}$ \\
\hline \multirow[t]{4}{*}{4} & $11 \mathrm{~d}$ & $11 \mathrm{~d}$ & $9 \mathrm{~d}$ & $9 \mathrm{~d}$ \\
\hline & $18 \mathrm{~d}$ & $18 \mathrm{~d}$ & $16 \mathrm{~d}$ & $16 \mathrm{~d}$ \\
\hline & $25 \mathrm{~d}$ & $25 \mathrm{~d}$ & $23 \mathrm{~d}$ & $23 \mathrm{~d}$ \\
\hline & $32 \mathrm{~d}$ & $32 \mathrm{~d}$ & $30 \mathrm{~d}$ & $30 \mathrm{~d}$ \\
\hline \multirow[t]{3}{*}{5} & $11 \mathrm{~d}$ & $11 \mathrm{~d}$ & $8 \mathrm{~d}$ & $8 \mathrm{~d}$ \\
\hline & $18 \mathrm{~d}$ & $18 \mathrm{~d}$ & $13 \mathrm{~d}$ & $13 \mathrm{~d}$ \\
\hline & $21 \mathrm{~d}$ & $21 \mathrm{~d}$ & $19 \mathrm{~d}$ & $19 \mathrm{~d}$ \\
\hline \multirow[t]{4}{*}{6} & $14 \mathrm{~d}$ & $14 \mathrm{~d}$ & $15 \mathrm{~d}$ & $15 \mathrm{~d}$ \\
\hline & $20 \mathrm{~d}$ & $20 \mathrm{~d}$ & $22 \mathrm{~d}$ & $22 \mathrm{~d}$ \\
\hline & $27 \mathrm{~d}$ & $27 \mathrm{~d}$ & $29 d$ & $29 \mathrm{~d}$ \\
\hline & $34 \mathrm{~d}$ & $34 \mathrm{~d}$ & $35 \mathrm{~d}$ & $35 \mathrm{~d}$ \\
\hline
\end{tabular}

\section{RESULTS}

Baseline parameters. There were no differences in the baseline measurements of postnatal age, weight, arterial blood gases, and hematocrit before each study of the systemic and local effects of PE and AVP. Thus, the baseline data were combined and are presented in Table 2 for each age period studied. Each animal gained weight during the study period, values increasing $\sim 40 \%$ ( $p<0.001$, ANOVA). Although the hematocrit was unchanged during the course of individual experiments, values fell $\sim 30 \%$ during the first postnatal month ( $p \leq 0.01$ ), likely reflecting the increase in plasma volume that normally occurs during this time (30). There also was an age-dependent rise in baseline MAP, fall in HR, and rise in FmBF that was associated with a $20-30 \%$ fall in FmVR (Tables 3 and 4). Because of variability between animals, the changes in FmBF and FmVR were only significant in the AVP studies ( $p \leq 0.03$, ANOVA; Table 4 ). Baseline hemodynamic

Table 2. Postnatal age, weight, arterial blood gases, and hematocrit for each age period prior to the systemic infusion of PE and AVP in postnatal conscious sheep

\begin{tabular}{lccc}
\hline & $7-14 \mathrm{~d}$ & $15-21 \mathrm{~d}$ & $22-35 \mathrm{~d}$ \\
\hline Postnatal age (d) & $11.3 \pm 0.6$ & $18.1 \pm 0.5$ & $28.8 \pm 1.3$ \\
Weight $(\mathrm{kg})$ & $6.1 \pm 0.3^{\mathrm{a}}$ & $7.2 \pm 0.3^{\mathrm{b}}$ & $8.5 \pm 0.4^{\mathrm{c}}$ \\
Arterial blood gases & & & \\
$\quad \mathrm{pH}$ & $7.42 \pm 0.003$ & $7.42 \pm 0.004$ & $7.42 \pm 0.003$ \\
$\mathrm{PCO}_{2}(\mathrm{~mm} \mathrm{Hg})$ & $35.8 \pm 0.4$ & $36.5 \pm 0.4$ & $35.6 \pm 0.2$ \\
$\mathrm{Po}_{2}(\mathrm{~mm} \mathrm{Hg})$ & $80.7 \pm 1.8$ & $82.3 \pm 1.0$ & $82.5 \pm 0.6$ \\
$\mathrm{Hematocrit}$ & $30.1 \pm 0.4^{\mathrm{a}}$ & $26.6 \pm 0.8^{\mathrm{b}}$ & $24.9 \pm 0.4^{\mathrm{c}}$ \\
\hline
\end{tabular}

Values are means \pm SEM. Data are derived from six newborn animals.

Different superscripts at postnatal ages (across rows) demonstrate significant differences in baseline data between age groups using repeated measures ANOVA, $p<0.05$; e.g., weight at 7-14 d differs from both 15-21 and 22-35 $\mathrm{d}$, which differ from each other. measurements obtained before the study of the effects of systemic and arterial infusions of PE or AVP demonstrated a similar pattern of change.

Responses to systemic PE and AVP infusions. The systemic infusion of PE resulted in a rise in MAP that achieved a steady-state response within 6-7 min and was associated with the simultaneous fall in HR and FmBF (Fig. 1A). Since there were age-dependent changes in basal hemodynamic parameters, the data were analyzed using the relative change from baseline $(\% \Delta)$, which permits a comparison across ages and between hemodynamic variables $(21,29)$. Although there were age-dependent differences in basal MAP and HR, there were no differences in baseline measurements obtained immediately before each dose of PE ( $p>0.05$, ANOVA) at each age. Systemic PE increased MAP with each dose studied (paired $t$ test, $p<0.01$ ) in a dose-dependent fashion at each age $(p<0.001$, ANOVA; Table 3). Notably, there were no differences in the responses between the three age groups (ANOVA, $p>0.05)$. The rise in MAP was associated with a decrease in HR with each dose $(p<0.05)$ that also was dose-dependent $(p<0.001$, ANOVA) and did not differ between age groups, demonstrating an intact baroreceptor response throughout the study period.

As with MAP and HR, baseline FmBF and FmVR before individual doses of PE did not differ within any age group. Systemic PE decreased FmBF dose dependently $(p<0.001$, ANOVA; Table 3) during each age period and was associated with a dose-dependent rise in FmVR $(p<0.001$, ANOVA). However, the responses in FmBF and FmVR did not differ between age groups. Because blood flow to a vascular bed generally reflects the simultaneous relative changes in perfusion pressure, i.e. MAP, and vascular resistance in that vascular bed $(21,26)$, we examined the simultaneous $\% \Delta$ MAP and $\% \Delta$ FmVR during systemic infusions of PE. At each dose of PE, the relative rise in FmVR consistently exceeded the increase in MAP, thereby explaining the observed fall in FmBF (Fig. 2).

The continuous systemic infusion of AVP also resulted in a rise in MAP that quickly achieved a steady state and was associated with a fall in $\mathrm{HR}$ and FmBF, resembling the pattern of responses seen with PE (Fig. 1A). As noted above, baseline hemodynamic variables before each dose and within each age period did not differ. Absolute changes in hemodynamic parameters during systemic AVP infusions are presented in Table 4.

Systemic AVP increased MAP with each dose studied (paired $t$ test, $p<0.04$ ) in a dose-dependent manner during each age period $(p<0.001$, ANOVA). HR also fell dose dependently $(p<0.001)$. However, as with PE, there were no significant differences between age groups in either the systemic pressor responses or fall in HR. Systemic AVP also decreased FmBF dose dependently ( $p<0.001$, ANOVA), and this was associated with a reciprocal dose-dependent rise in FmVR $(p<0.001$, ANOVA). Notably, the responses in FmVR and FmBF did not differ between age groups, and, as with PE, the rise in FmVR always exceeded the relative rise in MAP at each dose studied and at each age (Fig. 2). However, the AVP-induced increases in FmVR and MAP at each age were significantly less than those observed with PE $(p<0.05)$. 
Table 3. Effects of continuous intravenous PE infusions in conscious postnatal sheep on absolute values of MAP, HR, and FmBF and FmVR during the steady state in the first month postnatal

\begin{tabular}{|c|c|c|c|c|c|}
\hline & \multirow[b]{2}{*}{ Baseline } & \multicolumn{4}{|c|}{ Rate of infusion $(\mu \mathrm{g} / \mathrm{kg} \cdot \mathrm{min})$} \\
\hline & & 1.0 & 2.0 & 4.0 & 8.0 \\
\hline \multicolumn{6}{|c|}{ MAP (mm Hg) } \\
\hline $7-14 \mathrm{~d}$ & $78.5 \pm 0.8^{\mathrm{a}}$ & $83.3 \pm 2.1^{\mathrm{a}}$ & $91.0 \pm 2.3^{\mathrm{a}}$ & $102 \pm 3.4^{\mathrm{b}}$ & $121 \pm 4.3^{\mathrm{c}}$ \\
\hline $15-21 \mathrm{~d}$ & $84.0 \pm 1.0^{\mathrm{b}}$ & $93.3 \pm 4.3^{\mathrm{a}}$ & $102 \pm 4.4^{\mathrm{a}}$ & $113 \pm 4.9^{\mathrm{b}}$ & $133 \pm 5.7^{\mathrm{c}}$ \\
\hline $22-35 \mathrm{~d}$ & $82.3 \pm 0.8^{\mathrm{b}}$ & $89.0 \pm 2.3^{\mathrm{a}}$ & $102 \pm 4.7^{\mathrm{b}}$ & $107 \pm 3.5^{\mathrm{c}}$ & $124 \pm 5.9^{\mathrm{d}}$ \\
\hline \multicolumn{6}{|l|}{ HR (bpm) } \\
\hline $7-14 \mathrm{~d}$ & $193 \pm 5.2^{\mathrm{a}}$ & $153 \pm 10^{\mathrm{a}}$ & $137 \pm 8^{\mathrm{ab}}$ & $123 \pm 6^{\mathrm{b}}$ & $106 \pm 5^{b}$ \\
\hline $15-21 \mathrm{~d}$ & $150 \pm 5.7^{\mathrm{b}}$ & $129 \pm 13^{\mathrm{a}}$ & $115 \pm 11^{\mathrm{a}}$ & $100 \pm 9^{b}$ & $92.0 \pm 7^{\mathrm{b}}$ \\
\hline $22-35 \mathrm{~d}$ & $142 \pm 3.3^{b}$ & $115 \pm 5^{\mathrm{a}}$ & $101 \pm 6^{\mathrm{b}}$ & $91.0 \pm 3^{\mathrm{c}}$ & $81.0 \pm 2^{c}$ \\
\hline \multicolumn{6}{|c|}{ FmBF $(\mathrm{mL} / \mathrm{min})$} \\
\hline $7-14 \mathrm{~d}$ & $62.2 \pm 8.7$ & $54.3 \pm 18^{\mathrm{a}}$ & $55.3 \pm 21^{\mathrm{b}}$ & $54.0 \pm 17^{\mathrm{b}}$ & $48.7 \pm 19^{b}$ \\
\hline $15-21 \mathrm{~d}$ & $68.2 \pm 5.6$ & $59.5 \pm 11^{\mathrm{a}}$ & $54.7 \pm 12^{b}$ & $55.2 \pm 13^{b c}$ & $46.3 \pm 13^{\mathrm{c}}$ \\
\hline $22-35 \mathrm{~d}$ & $77.0 \pm 12$ & $64.8 \pm 21^{\mathrm{a}}$ & $58.8 \pm 17^{\mathrm{ab}}$ & $57.0 \pm 21^{\mathrm{ab}}$ & $55.0 \pm 24^{\mathrm{b}}$ \\
\hline \multicolumn{6}{|c|}{ FmVR (mm Hg/mL/min) } \\
\hline $7-14 \mathrm{~d}$ & $1.9 \pm 0.3$ & $2.3 \pm 0.6^{\mathrm{a}}$ & $3.4 \pm 1.4^{\mathrm{ab}}$ & $3.1 \pm 0.9^{\mathrm{b}}$ & $5.1 \pm 1.7^{\mathrm{c}}$ \\
\hline $15-21 \mathrm{~d}$ & $1.5 \pm 0.1$ & $1.9 \pm 0.4^{\mathrm{a}}$ & $2.7 \pm 0.7^{\mathrm{a}}$ & $2.8 \pm 0.7^{b}$ & $4.3 \pm 1.1^{\mathrm{c}}$ \\
\hline $22-35 \mathrm{~d}$ & $1.6 \pm 0.2$ & $2.0 \pm 0.4^{\mathrm{a}}$ & $2.7 \pm 0.9^{\mathrm{a}}$ & $3.5 \pm 1.2^{\mathrm{b}}$ & $4.5 \pm 1.8^{\mathrm{c}}$ \\
\hline
\end{tabular}

Values are mean $\pm \mathrm{SEM} ; n=5$ newborn animals for each age group.

Different superscripts across doses (rows) starting with 1.0 demonstrate significant differences between doses within each age using ANOVA for multiple groups, $p<0.05$.

Different superscripts under baseline (column 1) reflect significant differences between age groups using ANOVA, $p<0.05$.

Table 4. Effects of continuous intravenous AVP infusions in conscious postnatal sheep on absolute values of MAP, HR, and FmBF and FmVR during the steady state in the first month postnatal

\begin{tabular}{|c|c|c|c|c|c|}
\hline & \multirow[b]{2}{*}{ Baseline } & \multicolumn{4}{|c|}{ Rate of infusion $(\mathrm{mU} / \mathrm{kg} \cdot \mathrm{min})$} \\
\hline & & 0.97 & 1.29 & 2.56 & 5.18 \\
\hline \multicolumn{6}{|c|}{ MAP (mm Hg) } \\
\hline $15-21 d$ & $81.8 \pm 1.0^{\mathrm{b}}$ & $86.0 \pm 2.7^{\mathrm{a}}$ & $91.5 \pm 3.6^{\mathrm{b}}$ & $93.5 \pm 3.2^{\mathrm{c}}$ & $101 \pm 4.5^{\mathrm{d}}$ \\
\hline $22-35 \mathrm{~d}$ & $82.9 \pm 0.8^{\mathrm{b}}$ & $86.5 \pm 2.9^{\mathrm{a}}$ & $91.5 \pm 1.4^{\mathrm{b}}$ & $94.5 \pm 2.2^{\mathrm{b}}$ & $100 \pm 2.1^{\mathrm{c}}$ \\
\hline \multicolumn{6}{|l|}{ HR (bpm) } \\
\hline $7-14 \mathrm{~d}$ & $172 \pm 4.7^{\mathrm{a}}$ & $153 \pm 10^{\mathrm{a}}$ & $118 \pm 5^{\mathrm{b}}$ & $110 \pm 5^{\mathrm{b}}$ & $110 \pm 4^{\mathrm{b}}$ \\
\hline $22-35 \mathrm{~d}$ & $130 \pm 4.8^{\mathrm{a}}$ & $115 \pm 12^{\mathrm{a}}$ & $100 \pm 8^{\mathrm{b}}$ & $94 \pm 6^{\mathrm{b}}$ & $87.0 \pm 6^{\mathrm{b}}$ \\
\hline \multicolumn{6}{|c|}{$\mathrm{FmBF}(\mathrm{mL} / \mathrm{min})$} \\
\hline $7-14 \mathrm{~d}$ & $56.3 \pm 6.3^{\mathrm{a}}$ & $49.3 \pm 11^{\mathrm{a}}$ & $47.0 \pm 12^{\mathrm{b}}$ & $43.7 \pm 12^{\mathrm{b}}$ & $38.5 \pm 10^{\mathrm{c}}$ \\
\hline $15-21 \mathrm{~d}$ & $68.6 \pm 8.4^{\mathrm{b}}$ & $63.5 \pm 17^{\mathrm{a}}$ & $57.2 \pm 18^{\mathrm{a}}$ & $45.5 \pm 9.2^{\mathrm{b}}$ & $52.8 \pm 15^{\mathrm{b}}$ \\
\hline $22-35 \mathrm{~d}$ & $84.0 \pm 7.1^{\mathrm{b}}$ & $82.0 \pm 18^{\mathrm{a}}$ & $60.5 \pm 12^{\mathrm{b}}$ & $56.2 \pm 14^{\mathrm{bc}}$ & $51.2 \pm 11^{\mathrm{c}}$ \\
\hline \multicolumn{6}{|c|}{ FmVR $(\mathrm{mm} \mathrm{Hg} / \mathrm{mL} / \mathrm{min})$} \\
\hline $7-14 \mathrm{~d}$ & $1.8 \pm 0.2^{\mathrm{a}}$ & $2.1 \pm 0.3^{\mathrm{a}}$ & $2.6 \pm 0.6^{\mathrm{ab}}$ & $3.1 \pm 0.7^{\mathrm{b}}$ & $4.0 \pm 1.2^{\mathrm{c}}$ \\
\hline
\end{tabular}

Values are mean $\pm \mathrm{SEM} ; n=5$ for the first two age groups and $n=4$ for the last group.

Different superscripts across doses (rows) starting with 0.97 demonstrate significant differences between doses within each age using repeated measures ANOVA, $p<0.05$.

Different superscripts under baseline (column 1) reflect significant differences between age groups using repeated measures ANOVA, $p<0.05$.

Because the pressor responses to an agent involve several factors, including changes in PVR, we examined the relationship between the $\% \Delta$ MAP and $\% \Delta$ PVR, represented by FmVR, during the first postnatal month (Fig. 3). A linear relationship was evident at each age for each agent; however, the slopes of the linear regression for both agents were $<1.0$ for each age group and did not approximate the line of identity:

PE:

$7-14 \mathrm{~d}: \% \Delta \mathrm{MAP}=0.39(\% \Delta \mathrm{FmVR})+0.48, r=0.97$

$15-21 \mathrm{~d}: \% \Delta \mathrm{MAP}=0.27(\% \Delta \mathrm{FmVR})+6.90, r=0.99$

$22-35 \mathrm{~d}: \% \Delta \mathrm{MAP}=0.23(\% \Delta \mathrm{FmVR})+6.69, r=0.96$
AVP:

7-14 d: $\% \Delta \mathrm{MAP}=0.24(\% \Delta \mathrm{FmVR})+3.98, r=0.98$

$15-21 \mathrm{~d}: \% \Delta \mathrm{MAP}=0.25(\% \Delta \mathrm{FmVR})+2.52, r=0.99$

$22-35 \mathrm{~d}: \% \Delta \mathrm{MAP}=0.18(\% \Delta \mathrm{FmVR})+2.69, r=0.95$

Thus, alterations in cardiac output may have modified the increases in MAP. It is notable that the slopes of the curves (Fig. 3) appear to decrease with increasing age, suggesting an increasing cardiac effect with increasing age.

We also examined the baroreceptor responses at each postnatal age with both agents, using the relationship between the $\% \Delta$ MAP and $\% \Delta \mathrm{HR}$ (Fig. 4). The relationship between these parameters is shown by the following equations: 

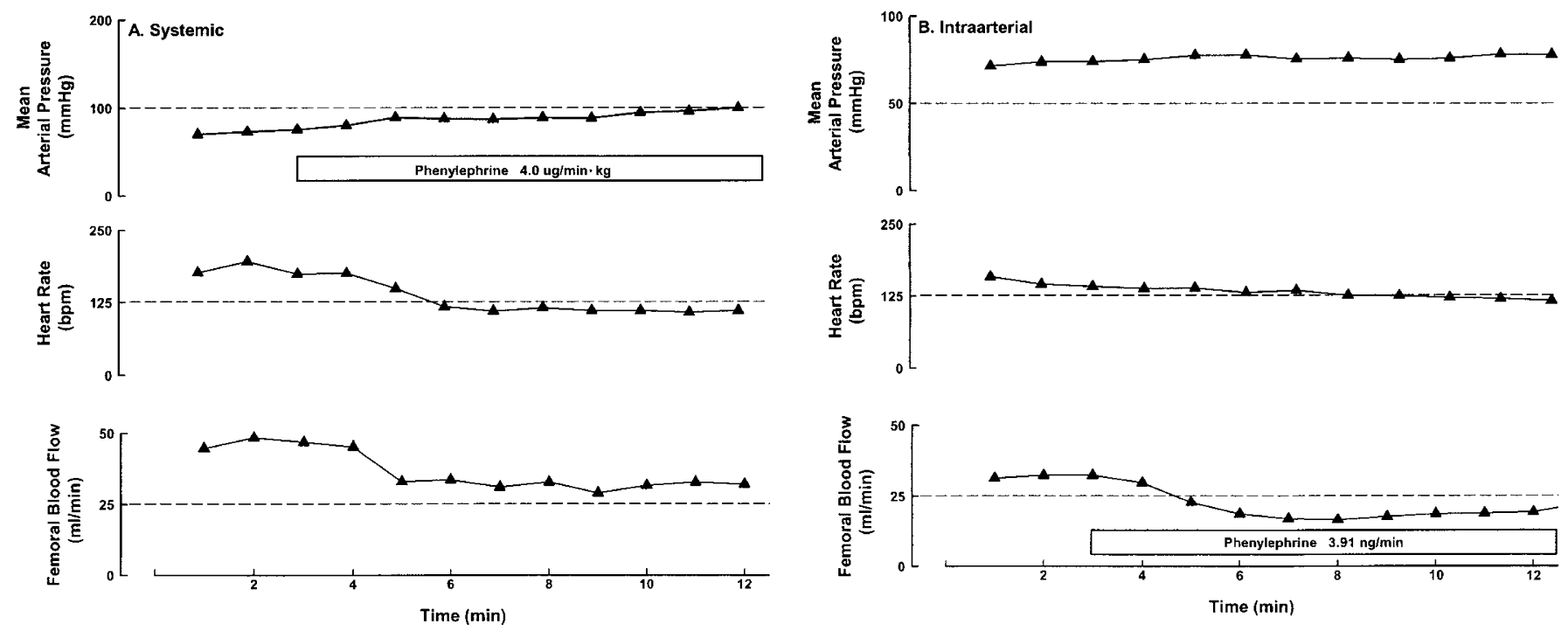

Figure 1. Representative tracings of the simultaneous hemodynamic responses to the continuous $(A)$ systemic and $(B)$ intra-arterial infusion of PE in a chronically instrumented conscious postnatal sheep at $11 \mathrm{~d}$ postnatal. The horizontal bars show the rate and duration of each PE infusion.

\section{PHENYLEPHRINE}
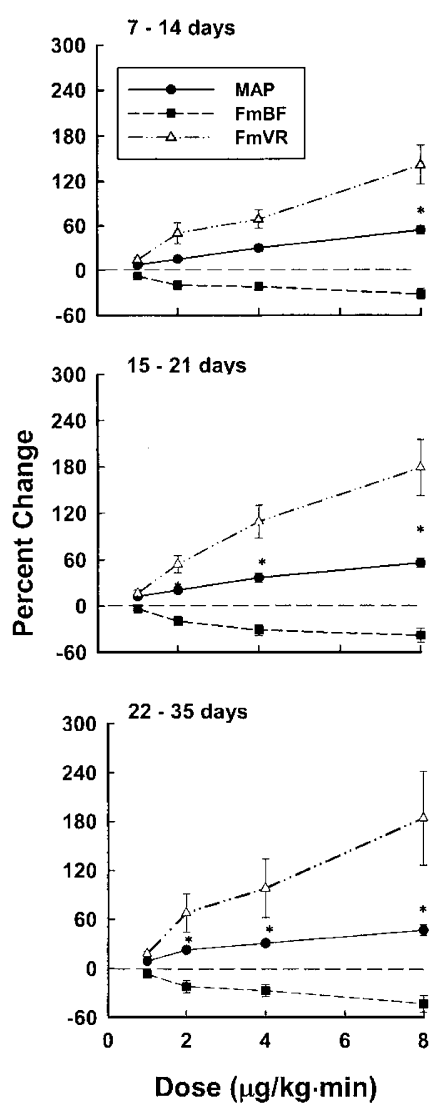

ARGININE VASOPRESSIN
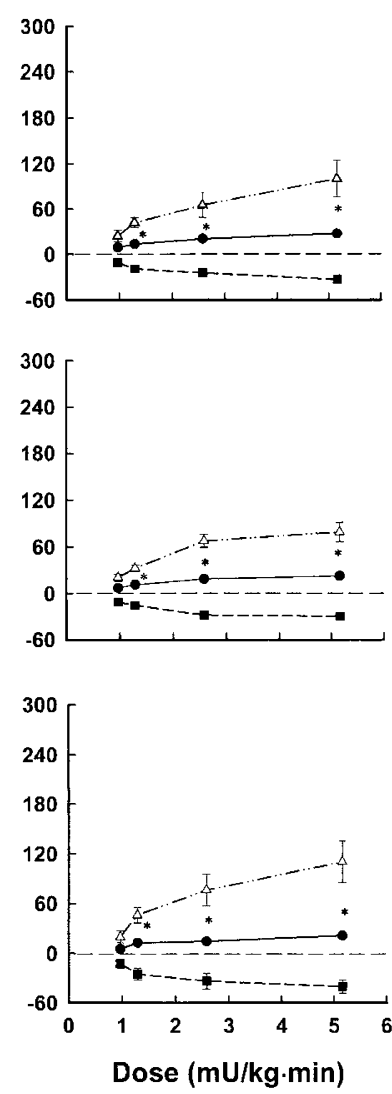

Figure 2. The relationship between the simultaneous relative changes in MAP, FmBF, and FmVR during systemic infusions of PE and AVP in conscious postnatal sheep at 7-14 d, 15-21 d, and 22-35 d after birth. Asterisks (*) represent significant differences between FmVR and MAP, $p<$ 0.05 by ANOVA. The number of animals in each age group for each drug is detailed in Tables 3 and 4.

PE

$$
\begin{aligned}
& 7-14 \mathrm{~d}: \% \Delta \mathrm{HR}=-0.4(\% \Delta \mathrm{MAP})-21.5, r=0.93 \\
& 15-21 \mathrm{~d}: \% \Delta \mathrm{HR}=-0.5(\% \Delta \mathrm{MAP})-9.9, r=0.95 \\
& 22-35 \mathrm{~d}: \% \Delta \mathrm{HR}=-0.5(\% \Delta \mathrm{MAP})-16.6, r=0.89 \\
& \mathrm{AVP} \\
& 7-14 \mathrm{~d}: \% \Delta \mathrm{HR}=-1.38(\% \Delta \mathrm{MAP})-4.9, r=0.91 \\
& 15-21 \mathrm{~d}: \% \Delta \mathrm{HR}=-1.81(\% \Delta \mathrm{MAP})-1.7, r=0.95 \\
& 22-35 \mathrm{~d}: \% \Delta \mathrm{HR}=-1.00(\% \Delta \mathrm{MAP})-9.7, r=0.99
\end{aligned}
$$

Both agents caused a rise in the $\% \Delta$ MAP and a reciprocal fall in $\% \Delta \mathrm{HR}$, demonstrating an intact baroreceptor response at each age that is not age-dependent. Although the PE-induced increases in MAP exceeded those with AVP $(p<0.05)$, the fall in HR was greater with AVP. This is consistent with prior observations that decreases in HR during systemic AVP infusions reflect baroreceptor responses plus a direct inhibitory effect of AVP on HR (19).

Responses to arterial infusions of $P E$ and AVP. Systemic infusions of PE and AVP induce systemic and local responses, and the former may modify local responses in blood flow through a variety of mechanisms (21). To determine the direct effect of each agonist on FmBF and FmVR in the absence of changes in perfusion pressure, we examined the hindlimb vascular responses to arterial infusions of both agents. A representative hemodynamic response to the arterial infusion of $\mathrm{PE}$ is shown in Figure $1 B$. As illustrated, there were decreases in FmBF in the absence of changes in MAP and HR. A similar pattern of response was observed with AVP. Intraarterial PE and AVP decreased FmBF in the absence of changes in MAP and HR at each age, demonstrating a direct vasoconstrictor response in the hindlimb. Furthermore, the fall in FmBF was associated with a parallel and proportionate rise in FmVR at each age (Fig. 5). In contrast to the responses observed during systemic infusions, there are no apparent differences between the responses to the two agents during 

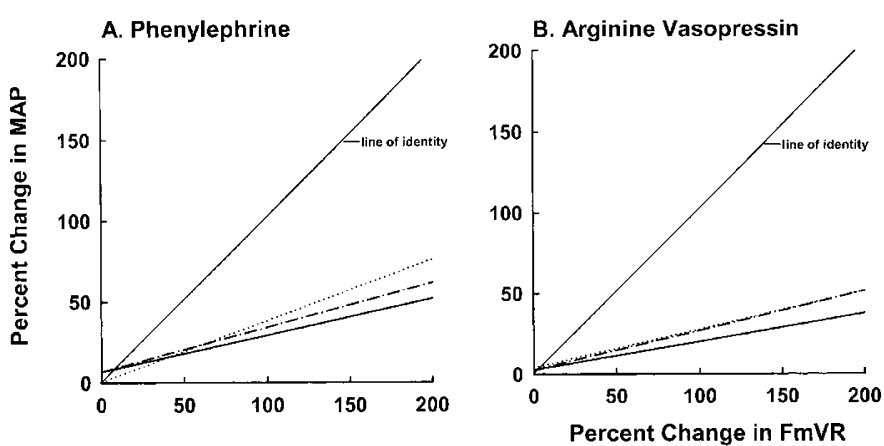

Figure 3. The relationship between the relative changes in MAP and FmVR during systemic infusions of (A) PE and (B) AVP in conscious postnatal sheep at 7-14 (dotted line), 15-21 (dot-and-dash line), and 22-35 (thick solid line) $\mathrm{d}$ after birth. The line of identity is shown. The number of animals in each age group for each drug is detailed in Tables 3 and 4 .
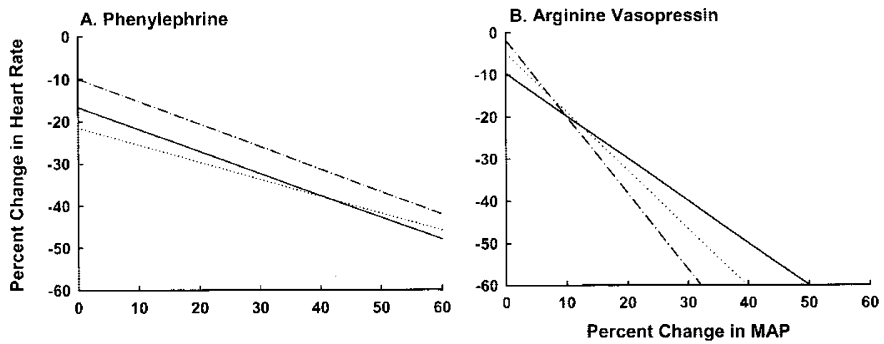

Figure 4. The relationship between the relative changes in HR and MAP during systemic infusions of (A) PE and (B) AVP in postnatal sheep at 7-14 (dotted line), 15-21 (dot-and-dash line), and 22-35 (thick solid line) $\mathrm{d}$ after birth. The number of animals in each age group for each drug is detailed in Tables 3 and 4.

arterial infusions. Moreover, the slopes appear to be similar, suggesting there is no an age-dependent effect:

$$
\begin{aligned}
& \text { PE } \\
& 7-14 \text { d: } \% \Delta \mathrm{FmVR}=0.33 \text { (Conc. })-5.25, r=0.71 \\
& 15-21 \text { d: } \% \Delta \mathrm{FmVR}=0.15 \text { (Conc. })+4.96, r=0.49 \\
& 22-35 \text { d: } \% \Delta \mathrm{FmVR}=0.15 \text { (Conc. })+4.96, r=0.49
\end{aligned}
$$

\section{AVP}

$7-14 \mathrm{~d}: \% \Delta \mathrm{FmVR}=0.91$ (Conc. $)+1.18, r=0.71$

$15-21$ d: $\% \Delta$ FmVR $=0.37$ (Conc.) $+11.1, r=0.55$

22-35 d: $\% \Delta \mathrm{FmVR}=0.18$ (Conc. $)+14.8, r=0.44$

\section{DISCUSSION}

The mechanisms that regulate MAP after birth remain unclear. Although ANG II was believed to make an important contribution, the AT2 receptor subtype persists in the peripheral VSM until 3-4 wk postnatal (13) and arterial ANG II infusions into the hindlimb have no direct effect on FmVR during this time (21). Thus, ANG II probably plays a minor role in directly modulating PVR in the fetus and newborn through the first postnatal month $(21,31)$, but may alter MAP through other mechanisms, including the release of other agonists (24-26). Although catecholamines and AVP may be important modulators of postnatal MAP, their effects on PVR remain unclear. That is, no one has compared responses to
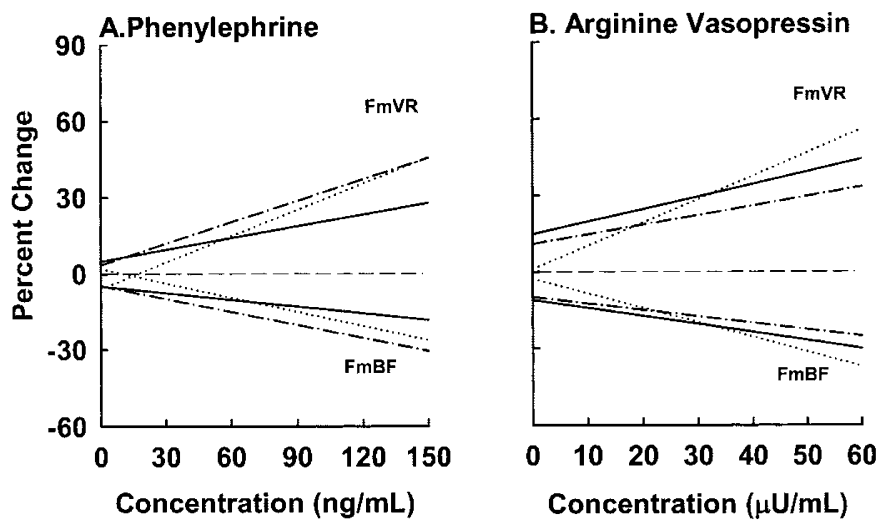

Figure 5. Comparison of the relative changes in FmBF and FmVR during intra-arterial infusions of (A) PE and (B) AVP in the hindlimb of conscious postnatal sheep at 7-14 (dotted line), 15-21 (dot-and-dash line), and 22-35 (thick solid line) after birth. The number of animals in each age group for each drug is detailed in Tables 3 and 4.

systemic and peripheral arterial infusions. In the present report, we performed serial studies in conscious postnatal sheep during the first 4-5 wk after birth, examining simultaneous changes in basal MAP, HR, FmBF, and FmVR during systemic and peripheral arterial infusions of PE and AVP. We observed 1) age-dependent increases in basal MAP and FmBF associated with decreases in HR and FmVR, 2) dose-dependent responses in MAP and FmBF during systemic PE and AVP infusions that were not age related, and 3) direct vasoconstrictor responses to $\mathrm{PE}$ and AVP that also were not age related. Thus, although it is possible that both agents may contribute to the regulation of newborn MAP, peripheral vascular sensitivity is unaltered, suggesting other mechanisms contribute to the postnatal rise in MAP.

In the present studies, we have confirmed earlier observations that basal MAP increases after birth, values nearly doubling by 7-14 $\mathrm{d}$ when compared with term fetal sheep $(2,17,22)$. Furthermore, values continue to rise and plateau after the second week postnatal, which is consistent with observations in both newborn sheep $(2,17,21)$ and preterm neonates $(8,9)$. It is unclear what facilitates this secondary rise in basal MAP. It could reflect increases in PVR, enhanced peripheral vascular sensitivity to circulating pressors such as ANG II, catecholamines or AVP, alterations in plasma levels of these agents, or modifications in cardiac output. It is notable that although MAP rose after birth, there was a tendency for PVR to fall, as reflected by decreases in FmVR and an increase in FmBF in the first month postnatal. It is possible the hindlimb is not representative of the peripheral vasculature as a whole and, therefore, does not mirror changes in total PVR.

Because MAP did not fall in association with the fall in basal FmVR, there must be alterations in cardiac output that maintain and/or increase MAP (15). Unfortunately, we did not measure cardiac output. It also is noteworthy that, similar to earlier observations (21), HR fell during the study period; therefore, one would suspect that if cardiac output increases, this is mediated by increases in stroke volume, which increases with postnatal age $(15,32)$.

After birth, basal HR fell as MAP rose. This provides evidence of an intact baroresponse that could be reset (33), or, 
as previously alluded to, could reflect an increase in parasympathetic activity $(17,34)$. Alternatively, there may be a change in the intrinsic conducting mechanisms within the heart (35). When we examined the baroresponse, it was intact at each age studied, but there was no apparent age-related response to either agonist, indirectly suggesting alterations in parasympathetic activity or cardiac conductivity. This is easier to assess with PE than AVP inasmuch as AVP also has a depressant effect on HR that is evident in these neonatal studies as well as prior studies in term fetal sheep (19).

Systemic infusions of PE and AVP dose-dependently increased MAP at all ages studied; however, as with ANG II (21), this was unchanged during the first month postnatal. Because increases in MAP reflect changes in PVR and/or cardiac output, we examined the role of peripheral vascular sensitivity. To address this, we continuously measured FmBF and calculated FmVR as a proxy for PVR. Although FmVR rose dose dependently and the increases at each dose and age exceeded the simultaneous relative rise in MAP, the responses also were not age dependent for PE or AVP. Thus, we have shown that, unlike ANG II, PE and AVP are potent direct peripheral vasoconstrictors. However, it is now apparent that peripheral vascular reactivity to these and other agents is unchanged during the first month postnatal $(14,21,36)$. This also appears to be true in preliminary studies of fetal and neonatal arterial rings (unpublished studies). We (37) recently observed this was not due to enhanced clearance of ANG II after birth. The clearance of infused $\alpha$-agonists and AVP after birth is unknown. It also was of interest that the increases in MAP and FmVR associated with systemic PE infusions exceeded that seen with AVP. However, this conclusion is limited by the fact that different doses and units of the two agonists were used. If this is real, the differences in pressor responses may reflect the depressant effect of AVP on HR, leading to a decrease in cardiac output. Because the $\% \Delta$ MAP is less with AVP, the buffering effect of perfusion pressure on the $\% \Delta$ FmVR might also be less. Thus, PE may be a more potent direct vasoconstrictor in the newborn hindlimb than AVP, or local or circulating vasodilators or antagonists modulate AVP responses, which can be addressed by removing the systemic effects of each agent.

To remove the effects of systemic infusions, we examined the direct vasoconstrictor effects of PE and AVP by infusing each agent directly into the arterial circulation of the hindlimb (21). If we had not done this in our studies of ANG II in fetal and newborn sheep $(21,31)$, we would have erroneously concluded that ANG II was a potent peripheral vasoconstrictor, raising important questions regarding the function of the AT2 receptor during development $(13,23)$. Unlike ANG II, both PE and AVP elicited direct effects on FmBF and FmVR in the absence of any systemic contribution. This clearly demonstrates that both agents are potent peripheral vasoconstrictors and their VSM receptors are present and functional. This also suggests that the VSM is mature and capable of eliciting a contraction response soon after birth that exceeds that seen in fetal animals (20). In contrast to that observed with systemic infusions, there were no differences in the hindlimb responses to either agent. Thus, systemic AVP infusions may induce the release of a circulating antagonist that attenuates the changes in PVR. This can be examined in future studies using this model.

In the present study, we have shown for the first time during the first month postnatal that, unlike ANG II $(21,31)$, PE and AVP are potent peripheral vasoconstrictors in conscious sheep and are capable of directly affecting PVR independent of changes in perfusion pressure. It is intriguing to speculate that, as in nonpregnant and pregnant adult animals $(25,26,38)$, these agents may mediate the pressor responses and increases in FmVR seen during systemic ANG II infusions (21) and thus mediate the contribution of the RAS to the regulation of vascular tone after birth. Similar to ANG II, there was no age-dependent increase in vascular sensitivity with either agent during the study period. Although persistent AT2 receptor expression in VSM may account for this with ANG II (13), the explanation for PE and AVP is not readily apparent and deserves further study. Nonetheless, these studies appear to exclude increases in PVR or VSM reactivity as an explanation for the rise in basal MAP observed during the first month after birth.

\section{REFERENCES}

1. Davidson D 1987 Circulating vasoactive substances and hemodynamic adjustments at birth in lambs. J Appl Physiol 63:676-684

2. Assali NS 1967 Some aspects of fetal life in utero and the changes at birth. Am J Obstet Gynecol 97:324-331

3. Chard T, Hudson CN, Edwards CR, Boyd NR 1971 Release of oxytocin and vasopressin by the human foetus during labour. Nature 234:352-354

4. Hoppenstein JM, Miltenberger FW, Moran WH Jr 1968 The increase in blood levels of vasopressin in infants during birth and surgical procedures. Surg Gynecol Obstet 127:966-974

5. Segar JL, Hajduczok G, Smith BA, Merrill DC, Robillard JE 1982 Ontogeny of baroreflex control of renal sympathetic nerve activity and heart rate. Am J Physiol 263:H1819-H1826

6. Klopfenstein HS, Rudolph AM 1978 Postnatal changes in the circulation and responses to volume loading in sheep. Circ Res 42:839-845

7. Assali NS, Brinkman CR 3rd, Woods JR Jr, Dandavino A, Nuwayhid B 1977 Development of neurohumoral control of fetal, neonatal, and adult cardiovascular functions. Am J Obstet Gynecol 129:748-759

8. LeFlore JL, Engle WD, Rosenfeld CR 2000 Determinants of blood pressure regulation in very low birth weight neonates: lack of effect of antenatal steroids. Early Hum Dev 59:37-50

9. Engle WD 2001 Blood pressure in the very low birth weight neonate. Early Hum Dev 62:97-130

10. Magness RR, Rosenfeld CR, Hassan A, Shaul PW 1996 Endothelial vasodilator production by uterine and systemic arteries. I. Effects of ANG II on PGI2 and NO in pregnancy. Am J Physiol 270:H1914-H1923

11. Yoshimura T, Rosenfeld CR, Magness RR 1991 Angiotensin II and $\alpha$-agonist. III. In vitro fetal-maternal placental prostaglandins. Am J Physiol 260:E8-E13

12. Agata Y, Padbury JF, Ludlow JK, Polk DH, Humme JA 1986 The effect of chemical sympathectomy on catecholamine release at birth. Pediatr Res 20:1338-1344

13. Cox BE, Rosenfeld CR 1999 Ontogeny of vascular angiotensin II receptor subtype expression in ovine development. Pediatr Res 45:414-424

14. Arens Y, Chapados R, Cox BE, Kamm KE, Rosenfeld CR 1998 Differential development of umbilical and systemic arteries II. Contractile proteins. Am J Physio 274:R1815-R1823

15. Woods JR Jr, Dandavino A, Brinkman CR 3rd, Nuwayhid B, Assali NS 1978 Cardiac output changes during neonatal growth. Am J Physiol 234:H520-H524

16. Wilson TA, Kaiser DL, Wright EM Jr, Ortt EM, Freedlender AE, Peach MJ, Carey RM 1981 Importance of plasma angiotensin concentrations in a comparative study of responses to angiotensin in the maturing newborn limb. Hypertension 3:II18-II24

17. Woods JR Jr, Dandavino A, Murayama K, Brinkman CR 3rd, Assali NS 1977 Autonomic control of cardiovascular functions during neonatal development and in adult sheep. Circ Res 40:401-407

18. Rose JC, Morris M, Meis PJ 1982 Development aspects of pituitary and adrenal responses to arterial hypotension in neonatal, weanling, and adult sheep. Am J Physiol 242:E215-E219

19. Wiriyathian S, Porter JC, Naden RP, Rosenfeld CR 1983 Cardiovascular effects and clearance of arginine vasopressin in the fetal lamb. Am J Physiol 245:E24-E31

20. Wyse DG, Van Petten GR, Harris WH 1977 Responses to electrical stimulation, noradrenaline, serotonin, and vasopressin in the isolated ear artery of the developing lamb and ewe. Can J Physiol Pharmacol 55:1001-1006

21. Velaphi SC, Roy T, DeSpain K, Rosenfeld CR 2002 Differential responses to systemic and local angiotensin II infusions in conscious postnatal sheep. Pediatr Res 52:333-341 
22. Wilson TA, Kaiser DL, Wright EM Jr, Peach MJ, Carey RM 1981 Ontogeny of blood pressure and the renin-angiotensin-aldosterone system: Sequential studies in newborn lamb. Circ Res 49:416-423

23. Bottari SP, de Gaspero M, Steckelings UM, Levens NR 1993 Angiotensin II receptor subtypes: characterization, signalling mechanisms, and possible physiological implications. Front Neuroendocrinol 14:123-171

24. Shi L, Hu F, Morrissey P, Yao J, Xu Z 2003 Intravenous angiotensin induces brain c-fos expression and vasopressin release in the near-term ovine fetus. Am J Physiol Endocrinol Metab 285:E1216-E1222

25. Cox BE, Williams CE, Rosenfeld CR 2000 Angiotensin II indirectly vasoconstricts the ovine uterine circulation. Am J Physiol Regul Integr Comp Physiol 278:R337-R344

26. Cox BE, Roy TA, Rosenfeld CR 2004 Angiotensin II mediates uterine vasoconstriction through alpha-stimulation. Am J Physiol Heart Circ Physiol 287:H126-H134

27. Nuwayhid B, Brinkman CR 3rd, Su C, Bevan JA, Assali NS 1975 Systemic and pulmonary hemodynamic responses to adrenergic and cholinergic agonists during fetal development. Biol Neonate 26:301-317

28. Yoshimura T, Magness RR, Rosenfeld CR 1990 Angiotensin and $\alpha$-agonist. Responses of ovine fetoplacental vasculature. Am J Physiol 259:H464-H472

29. Naden RP, Rosenfeld CR 1981 Effect of angiotensin II on uterine and systemic vasculature in pregnant sheep. J Clin Invest 68:468-474

30. Brans YW, Andrew DS, Schwartz CA, Carey KD 1991 Serial estimates of body water content and distribution during the first postnatal month in baboons. J Med Primatol 20:75-81
31. Kaiser JR, Cox BE, Roy TA, Rosenfeld CR 1998 Differential development of umbilical and systemic arteries. I. ANG II receptor subtype expression. Am J Physio 274:R797-R807

32. Minoura S, Gilbert RD 1987 Postnatal change of cardiac function in lambs: effects of ganglionic block and afterload. J Dev Physiol 9:123-135

33. Segar JL 1997 Ontogeny of the arterial and cardiopulmonary baroreflex during fetal and postnatal life. Am J Physiol 273:R457-R471

34. Zugaib M, Forsythe AB, Nuwayhid B, Lieb SM, Tabsh K, Erkkola R, Ushioda E, Brinkman CR 3rd, Assali NS 1980 Mechanisms of beat-to-beat variability in the heart rate of the neonatal lamb. I. Influence of the autonomic nervous system. Am J Obstet Gynecol 138:444-452

35. Levy MN, Zieske H 1969 Autonomic control of cardiac pacemaker activity and atrioventricular transmission. J Appl Physiol 27:465-470

36. Nuyt AM, Segar JL, Holley AT, O'Mara MS, Chapleau MW, Robillard JE 1996 Arginine vasopressin modulation of arterial baroreflex responses in fetal and newborn sheep. Am J Physiol 271:R1643-R1653

37. Rosenfeld CR, Velaphi SC, DeSpain K, Roy T 2003 Changes in the renin-angiotensin system in the conscious postnatal sheep during the first month after birth. Pediatr Res 53:146A

38. Rosenfeld CR 2001 Mechanisms regulating angiotensin II responsiveness by the uteroplacental circulation. Am J Physiol Regul Integr Comp Physiol 281:R1025-R1040 